Putting Proverbs to the Test: An Engaging Approach for Developing Students' Hypothesis Testing Skills

\author{
Tim Gamble* \\ Department of Psychology, University of Winchester, Winchester SO22 4NR, UK \\ Julie M. Turner-Cobb \\ Department of Psychology, Bournemouth University, Poole BH12 5BB, UK \\ Ian Walker \\ Department of Psychology, University of Bath, Bath BA2 7AY, UK
}

Nigel Holt

Department of Psychology, Aberystwyth University, Aberystwyth SY23 3FL, UK

*Corresponding author.+44 (0) 1962 624943, tim.gamble@winchester.ac.uk

Word count: 2841 


\begin{abstract}
Integral to most undergraduate psychology degree programs are research methods courses. Students learn about theory, study design and hypothesis testing, and gain knowledge that is assessed by laboratory reports. We describe a problem-based learning approach with an emphasis on acquisition of study design skills. Working in small groups, students took wellknown falsifiable proverbs, developed hypotheses to test them, recruited and assessed participants, analyzed the data, and presented their findings in a poster format. This approach allowed students to develop key skills to systematically experiment with an idea using proverbs as a proxy for theory. We suggest proverb testing as a useful technique to engage student-centered active learning in psychology and in the behavioral sciences more broadly.
\end{abstract}

Keywords: research methods, poster presentation, proverbs, problem-based learning, hypothesis testing 


\section{Putting Proverbs to the Test: An Engaging Approach for Developing Students' Hypothesis Testing Skills}

A course in quantitative research methods is the cornerstone of most undergraduate psychology degree programs (Perlman \& McCann, 2005; Stoloff et al, 2010). Such courses offer an introduction to the scientific method and research process, and students are frequently assessed on the knowledge and skills acquired by a series of laboratory reports (Harris, 2008). Through sequential formative feedback from these reports, the goal is for students to incrementally gain an understanding of how to conduct research and analyze data, improve their writing style and learn to critique and assess work conducted using the experimental method.

While many research method lectures take traditional approach of providing information through passive observation, students are often expected to play an active role in the learning process e.g. via data collection and analysis, and self-directed reading (LaCosse et al., 2017). Active learning fits with a range of process approaches, including Knowles, Holton and Swanson's (2005) andragogical process model, where learners are provided with experiences by teachers/facilitators or a constructivist approach which centers on the idea that learners use activity to construct knowledge, and teachers and facilitators define the activities students engage in to achieve the required learning outcomes (Biggs \& Tang, 2007). Indeed, experiential learning, through the resolution of conflicts and tensions (Kolb, 1984), provides a foundation for continued lifelong learning. An additional strategy for the instruction of research methods is the problem-based learning approach (Karpiak, 2011). Barrows (1996, pp. 5-6) defined this student-centered approach as one in which "problems form the organizing focus and stimulus for learning” citing it as a particularly useful "vehicle for the development of clinical problem-solving skills”. 
However, despite the merits of a small group, student centered, problem solving approach to research methods teaching, it can be difficult to find a suitable number of distinct and discrete mini experiments that provide sufficient challenge in designing a study from conception to completion. Previous attempts to resolve this problem have used astrology (Ward \& Grasha, 1986), examples from the television program “Mythbusters” (Burkley \& Burkley, 2009) and the testing of pseudoscientific claims (LoSchiave \& Roberts, 2005) to provide material. Here, we attempt to address this issue by using proverbs.

The study and collection of proverbs, known as paremiology, can help provide a solution to this dilemma. Proverbs (adages/idioms) are usually well-known, short sayings that express a thought, piece of advice or truth. Proverbs have a long and varied history in psychology; for example, in personality testing (Mieder, 1978), assessing perceived truthfulness (Furnham, 1987) and understanding abstract intelligence (Gibbs \& Beitel, 1995). Studies have also questioned whether they can serve as theories (Rogers, 1990) or hypotheses (Dion, 1990). Rolls (2007) wrote a popular psychology book exploring the background and truthfulness of many common proverbs. Rogers (1990) noted that whereas proverbs can be made up of relatively concrete words, the meaning they convey can be more abstract or polysemetic; an “abstract/concrete duality” (Rogers, 1990, p. 196). Because they can be interpreted as having multiple and/or contradictory meanings, proverbs are particularly interesting and novel as a source material for theories to be tested in the classroom. Grant and Asimeng-Boahene (2006) suggested using African proverbs in the teaching of citizenship to children in schools. They argued that proverbs can be valuable teaching tools because they provide insight into events and points of view outside of the traditional field, encourage the use of analytical skills, and help explain and illustrate the complexity of cultural knowledge. Additionally, testing proverbs as theories can facilitate the analysis of wider cultural knowledge and wisdom. 
The existence of a substantial repository of proverbs provides a rich source of material for use in the classroom, giving a wide range of easily accessible ideas for students to pursue. This abundance of material facilitates not only the avoidance of duplication within a large cohort but importantly provides a proxy for psychological theory that is useful for students early in their learning. Proverbs serve as naïve or simple theories and enable students to work effectively in groups to interpret the saying and to create a suitable hypothesis to test it. Testing proverbs allows students to hone their methodological skills by learning how to assess a falsifiable hypothesis through systematic application of study design principles. This approach can be an efficient way of teaching the link between theory and hypotheses in the broader context of research design, with existing psychological theory integrated to develop rationale and methodology.

The design of the exercise described here is student-centered; students worked in small groups and were expected to take responsibility for their own learning. The 'problem', how to adequately test a theory based on a proverb, formed the focus and stimulus for learning. Students acquired the necessary information and skills to complete the task through self-directed learning and added to prior knowledge and skills acquired earlier in the course.

The overall aim of the unit in which the proverbs exercise took place was to provide students with the basic skills required for designing, conducting and reporting experimental research in psychology. The unit's four intended learning outcomes were to be: (a) familiar with the basic principles of research design and sampling; (b) able to consider ethical issues relevant to research in psychology; (c) able to write and format psychological laboratory reports according to APA guidelines; and (d) able to plan and conduct a psychology experiment. Although our focus is on the research-specific skills learned using proverb testing, a range of other more generic, transferrable skills (Fallows \& Steven, 2000) or generic graduate attributes (Barrie, 2006) were also learned in the process, and including 
presentation skills, use of statistics (Daniel \& Braasch, 2013), team working, writing and information technology skills and personal attributes such as self-belief.

The current exercise consisted of developing a hypothesis to test a proverb as if it were a theory, designing and conducting a relevant study and producing a poster to present the findings. The exercise is presented as an alternative or complement to writing laboratory reports in undergraduate psychology research methods classes. A standard poster presentation was used as the assessment for this task; the merits of such a task have been extensively documented in the literature (Chute \& Bank, 1983; Hughes, 2005; Marek, Christopher \& Koenig, 2002; Moule, Judd \& Girot, 1998).

\section{The proverbs exercise}

Class introduction and context. We introduced the proverb exercise during the first lecture of the second semester of a two-semester, first-year research methods course at a three-year undergraduate degree program at a UK university. Students were all psychology majors. When the exercise was initiated, there were 70 students enrolled in the year, rising to 160 students 5 years later. The previous semester of the course consisted of nine lectures plus two laboratory sessions and covered the core elements of research methods. Students had already submitted two laboratory reports at the point when the proverb exercise was introduced. Teaching of quantitative statistics occurred in a separate course running in parallel with the methods course in the second semester.

Students had the task explained to them with a clearly articulated, achievable goal timeframe. They were informed that six of the class sessions would involve working in groups on their poster projects, with the expectation that they would also work on the task outside of class. Students were shown posters from previous year groups with guidance given on how to produce an effective poster. 
Group formation. Random assignment rather than self-assignment to groups was used to avoid problems associated with friendship group clusters and to reflect the reality of situations encountered in a work environment. To enable equal distribution of tasks, group membership was optimized as 5-6 students; each group was asked to provide a team name to increase a sense of ownership and participatory involvement.

Proverb selection. There are a large number of proverbs, as illustrated by the 1559 painting "Netherlandish Proverbs” by Pieter Bruegel the Elder (see Figure 1). The painting depicts over 100 identifiable proverbs and idioms from the Netherlands, some of which are still recognizable to an English-speaking audience (such as 'to bang your head against a brick wall' or 'the die is cast'). To generate a list of proverbs and facilitate selection, a list of proverbs previously approved by the unit coordinators was developed. Student groups could select proverbs from this list. Alternatively, groups could choose their own proverb, such as one unique to an international student's country. In subsequent cohorts, proverbs were randomly preassigned to each group for a simpler and fairer approach to selection.

\section{(Netherlandish Proverbs picture goes here)}

Figure 1. Netherlandish Proverbs, by P. Bruegel the Elder, 1559, http://www.wikiart.org/en/pieter-bruegel-the-elder/netherlandish-proverbs-1559. Public domain.

Hypothesis generation. Students developed a hypothesis based on their chosen proverb. Because proverbs can be interpreted in several ways, there was considerable scope for the development of the hypothesis. For example, the proverb 'Many hands make light work' could be operationalized as a test of group size on task outcomes to determine whether 
increased group size makes the task easier for all, or alternatively it could be used to assess whether increased group size leads to “social loafing” (Latané, Williams \& Harkins, 1979). Flexibility of interpretation gives students the opportunity to direct their focus and bring in relevant psychological literature to help justify the rationale for their hypothesis when interpreting their findings. It was made clear to the students that the proverbs merely served as simple theories, and that within the scientific method, hypotheses are typically grounded in a theoretical framework.

Study design. Once an appropriate hypothesis had been chosen, the groups created an adequate study design to test their hypothesis. They used either simple experimental or correlational methods appropriate to the hypotheses generated by the proverbs, at the level of their current knowledge of research methods and statistical analysis. Lecturers and postgraduate teaching assistants were available to assist with study design, including such issues as overly optimistic material requirements and unfeasible complexity. It was made clear at this stage that different lecturers or teaching assistants might have differing approaches to the design and that there is often no one "correct” answer to a given problem.

Ethics. Each group wrote an ethics application, detailing the procedures, materials and intended sample, highlighting any potential ethical issues related to their study. All applications were required to be approved by a member of the Psychology Department's ethics board prior to data collection and to adhere to the British Psychological Society’s (2014, 2018) ethical procedures.

Recruitment of participants. The student cohort taking the unit served as the participant pool for one another; students were not permitted to recruit from outside the class.

Testing. Students could request to be allocated a time within an existing research methods or statistics class to conduct testing as long as it required only minimal disruption and testing time was brief. Other groups with more involved individual testing were able to 
gather data in timetabled group work sessions. Individual groups were expected to manage their own time during testing, with each experiment required to run for no longer than 5-10 minutes per participant. Many groups were able to collect data online, within the designated participant pool.

Statistical analysis. Each group conducted their own statistical analyses, with guidance where necessary. Students whose designs required the use of more complex analyses, beyond those covered in parallelly conducted quantitative methods classes, were encouraged to simplify their design.

Poster preparation. Groups produced a professionally printed poster for their study. We provided students with guidance about content and design, made example posters available for reference, and provided a template to ensure consistency.

\section{Examples of two proverbs chosen and tested}

1) “The more the merrier”. The students interpreted this proverb as an insight into materialism, with the hypothesis that there would be a positive correlation between number of pairs of shoes owned and happiness. Sixty-four participants reported the number of pairs of shoes owned and completed a happiness scale. Observing a significant positive correlation, the students discussed limitations and concluded that the finding could influence future shoe marketing strategies.

2) "You can’t judge a book by its cover”. Interpreting the proverb as a form of stereotyping, students investigated whether hair color affected perceptions of female intelligence. In a repeated-measures design, 81 participants were shown 5 computerized faces twice in random order, once with blonde hair coloring and once with brunette hair coloring, rating intelligence using a 10-point scale. The mean intelligence score for blonde hair coloring was significantly lower than the mean for brunette hair coloring, with the students concluding that stereotyping was observed in the sample. 
Poster presentations. A poster conference was facilitated to allow each group to present their work and respond to comments and queries from those grading the posters and from other interested members of staff and postgraduate students.

Assessment. Assessment covered three components of the posters: i) scientific content (research design and methodology); ii) appearance (visual effectiveness and information); and iii) verbal presentation (of poster content and ability to answer questions). Each group was given an overall summative score and formative feedback on each component.

\section{Evaluation of the task}

Using end-of-semester qualitative unit feedback from the first 5 years after the exercise was introduced and a "stop-start-continue” exercise (Hoon, Oliver, Szpakowska \& Newton, 2015) from one of these years, we examined the responses that referred specifically to the proverb exercise. Overall, the proportion of unit feedback from students that referred to the proverb task was about 25\%, roughly reflecting the assessment weighting of one out of five assignments in the unit. We firstly considered the content of and frequency with which positive and negative descriptions of the proverb task were used, and then reviewed evidence of the efficacy of the task for achieving the learning objectives of the unit.

Feedback indicated that students were very satisfied with the proverb exercise $(86 \%$ of comments were positive) using adjectives such as “enjoyed,” “simulating,” “fun,” and "brilliant”. They commented that the experience enabled "novelty," “freedom,” “individuality” and “creativity”. Negative comments referred more often to assessment of the task and to grading criteria or focused on issues of perceived 'social loafing' within groups rather than the proverb task itself. Only two comments over the 5 years demonstrated a dislike of the exercise due to learning style. Table 1 provides example quotes that align to the overall aim of the unit and each of the four intended learning outcomes. These comments provide evidence that the proverbs exercise met the pedagogical goals. 
Insert table 1 about here

In addition to student satisfaction and efficacy of the task for learning objectives, students also highlighted several transferable skills; organizational and time management, group work and dynamics, presentation and communication, development of critical and analytical ability, and use of information technology. Students specifically mentioned that they had improved their skillset on several levels, that the skills they had learned were necessary and different than those they usually learnt. They pointed out that they recognized these skills as having the potential to become in useful in the future.

\section{Conclusion}

The proverb testing method of teaching described here aimed to use an active-learning, problem-solving method and provide an alternative to traditional laboratory reports. As well as producing high quality posters, the use of proverbs was successful in enabling students to develop hypothesis testing skills in an applied context and relatively novel assessment setting. For our purposes, we focused more on hypothesis testing than theory development and one benefit of the proverb testing approach is that it requires less extensive immersion in theory. There is significant potential for future application of proverbs for hypothesis testing, including greater emphasis on the incorporation of theory in the early stages of hypothesis generation, and choosing proverbs that lend themselves to theoretical approaches. The utility of the method could extend beyond psychology, to provide a novel, engaging, and accessible technique with which to develop the principles of hypothesis testing in the behavioral sciences more broadly. 
Here we used proverb testing as a framework for teaching broader research methods skills but proverbs may also be effective in smaller scale teaching contexts, as an in-class activity or brief assignment for teaching operational definitions. The evaluation of our proverb testing approach was relatively minimal. Future work would benefit from more indepth evaluation in order to assess the efficacy of the task in comparison with more traditional laboratory report style assessments.

In sum, the use of proverbs in a higher education setting was found to have benefits in relation to hypothesis testing, and many of the generic characteristics that emerged reveal proverbs to have multiple pedagogical applications. We would call for development of these applications to benefit learners across a wide range of disciplines and backgrounds; after all, a picture (visual image or story) really is worth a thousand words, especially as a pedagogical tool. 


\section{Acknowledgements}

The authors wish to thank the anonymous reviewers and Katharine Mcatamney for their comments on earlier drafts of this paper, all the undergraduate students who participated in the classes, and the postgraduate teaching assistants who aided in the delivery of the sessions and grading of the posters. 


\section{References}

Barrie, S. C. (2006). Understanding what we mean by the generic attributes of graduates. Higher Education, 51, 215-241. doi:10.1007/s10734-004-6384-7

Barrows, H. S. (1996). Problem-based learning in medicine and beyond: A brief overview. New Direction for Teaching and Learning, 68, 3-12. doi:10.1002/tl.37219966804

Biggs, J., \& Tang, C. (2007). Teaching for quality learning at university (3rd ed.). London, UK: Open University Press.

British Psychological Society. (2014). Code of Human Research Ethics. Retrieved from https://www.bps.org.uk/news-and-policy/bps-code-human-research-ethics-2nd-edition2014

British Psychological Society. (2018). Code of Ethics and Conduct. Retrieved from https://www.bps.org.uk/news-and-policy/bps-code-ethics-and-conduct

Bruegel the Elder, P. (1559). Netherlandish Proverbs [Painting]. Retrieved from http://www.wikiart.org/en/pieter-bruegel-the-elder/netherlandish-proverbs-1559

Burkley, E., \& Burkley, M. (2009). Mythbusters: A tool for teaching research methods in psychology. Teaching of Psychology, 36, 179-184. doi:10.1080/00986280902739586

Chute, D., \& Bank, B. (1983). Undergraduate seminars: The poster session solution. Teaching of Psychology, 10, 99-100. doi:10.1207/s15328023top1002_11

Daniel, F., \& Braasch, J. L. (2013). Application exercises improve transfer of statistical knowledge in real-world situations. Teaching of Psychology, 40, 200-207. doi:10.1177/0098628313487462

Dion, K. L. (1990). Psychology and proverbs: Folk psychology revisited. Canadian Psychology/Psychologie canadienne, 31, 209-211. doi:10.1037/h0078913

Fallows, S. J., \& Steven, C. (2000). Integrating key skills in higher education: Employability, transferable skills and learning for life. London, UK: Kogan Page. 
Furnham, A. (1987). The Proverbial Truth: Contextually Reconciling and the Truthfulness of Antonymous Proverbs. Journal of Language and Social Psychology, 6, 49-55. doi:10.1177/0261927X8700600103

Gibbs, R. W., \& Beitel, D. (1995). What proverb understanding reveals about how people think. Psychological Bulletin, 118, 133-54. doi:10.1037/0033-2909.118.1.133

Grant, R. A., \& Asimeng-Boahene, L. (2006). Culturally responsive pedagogy in citizenship education: Using African proverbs as tools for teaching in urban schools. Multicultural Perspectives, 8, 17-24. doi:10.1207/s15327892mcp0804_4

Harris, P. (2008). Designing and reporting experiments in psychology (3rd ed.). Madidenhead, UK: McGraw-Hill Education.

Hoon, A., Oliver, E., Szpakowska, K., \& Newton, P. (2015). Use of the 'Stop, Start, Continue' method is associated with the production of constructive qualitative feedback by students in higher education. Assessment \& Evaluation in Higher Education, 40, 755-767. doi:10.1080/02602938.2014.956282

Hughes, A. (2005). A poster project for an undergraduate sensation and perception course. Teaching of Psychology, 32, 58-59. doi:10.1207/s15328023top3201_11

Karpiak, C. P. (2011). Assessment of problem-based learning in the undergraduate statistics course. Teaching of Psychology, 38, 251-254. doi:10.1177/0098628311421322

Knight, P. T., \& Yorke, M. (2002). Employability through the curriculum. Tertiary Education and Management, 8, 261-276. doi:10.1080/13583883.2002.9967084

Knowles, M. S., Holton, E. F. III, \& Swanson, R. A. (2005). The adult learner: The definitive classic in adult education and human resource development (6th ed.). Boston: Elsevier.

Kolb, D. A. (1984). Experiential learning: Experience as the source of learning and development. USA: Prentice Hall. 
LaCosse, J., Ainsworth, S. E., Shepherd, M. A., Ent, M., Klein, K. M., Holland-Carter, L. A., ... \& Licht, B. (2017). An active-learning approach to fostering understanding of research methods in large classes. Teaching of Psychology, 44, 117-123. doi:10.1177/0098628317692614

Latané, B., Williams, K., \& Harkins, S. (1979). Many hands make light the work: The causes and consequences of social loafing. Journal of Personality and Social Psychology, 37, 822-832. doi:10.1037/0022-3514.37.6.822

LoSchiavo, F. M., \& Roberts, K. L. (2005). Testing pseudoscientific claims in research methods courses. Teaching of Psychology, 32, 177-180. doi:10.1207/s15328023top3203_10

Marek, P., Christopher, A. N., \& Koenig, C. S. (2002). Applying technology to facilitate poster presentations. Teaching of Psychology, 29, 70-72. doi:10.1207/S15328023TOP2901_12

Mieder, W. (1978). The Use of Proverbs in Psychological Testing, Journal of the Folklore Institute, 15, 45-55. doi:10.2307/3814137

Moule, P., Judd, M., \& Girot, E. (1998). The poster presentation: What value to the teaching and assessment of research in pre- and post-registration nursing courses? Nurse Education Today, 18, 237-242. doi:10.1016/S0260-6917(98)80085-3

Perlman, B., \& McCann, L. I. (2005). Undergraduate research experiences in psychology: A national study of courses and curricula. Teaching of Psychology, 32, 5-14. doi:10.1207/s15328023top3201_2

Rogers, T. B. (1990). Proverbs as psychological theories... or is it the other way around? Canadian Psychology/Psychologie canadienne, 31, 195-207. doi:10.1037/h0078917 Rolls, G. W. P. (2007). Taking the proverbial: The psychology of proverbs and sayings. Edinburgh, UK: Chambers. 
Stoloff, M., McCarthy, M., Keller, L., Varfolomeeva, V., Lynch, J., Makara, K., ... Smiley, W. (2010). The undergraduate psychology major: An examination of structure and sequence. Teaching of Psychology, 37, 4-15. doi:10.1080/00986280903426274

Ward, R. A., \& Grasha, A. F. (1986). Using astrology to teach research methods to introductory psychology students. Teaching of Psychology, 13, 143-145. doi:10.1207/s15328023top1303_11 
Table 1

Example student feedback quotes aligning to the unit's overall aim and intended learning outcomes (ILO), and proverb specific comments relating to pedagogy and transferable skills

Theme by aim, ILO and proverb Student quote identifying skills learnt specific comments

Overall unit aim: To provide students with the basic skills required for designing, conducting and reporting experimental research in psychology

ILO1: Be familiar with the basic principles of research design and sampling

ILO2: Be able to consider ethical issues relevant to research in psychology

ILO3: Be able to write and format psychological laboratory reports according to APA guidelines

ILO4 Be able to plan and conduct
"The poster presentations were a good way of advancing understanding.”

"The poster presentations were a nice change of assessment from all of the lab reports that we have to do, maybe used less lab reports for assessment and more alternative methods like this to add more variation and opportunity to display different skills”

(cited skills learnt) "Stats understanding, team building and communication”

“...learned about ethical considerations in experiments and working in groups"

(cited skills learnt) "interpreting statistics and applying them, evaluating a study, writing to an academic standard.” "learned how to present graphs, tables and references in APA format...”

"Conducting our own experiment was good fun - maybe do this a bit 
a psychology experiment

Proverb specific comment relating to pedagogy

Proverb specific comment relating to transferable skills more?”

"The poster presentation was a really interesting form of assessment and I thoroughly enjoyed devising and carrying our own research studies.”

"The poster presentation was fun and yet stimulating at the same time!”

"Producing a professional-looking poster was great practice and quite good fun. The presentation itself was also very good practice. I did enjoy the novelty factor of testing proverbs and feel that novel hypotheses should continue to be tested." (continue) "the poster presentation is good. $\mathrm{i}$ like that we start it really early and continue it through many weeks so that its not so rushed towards the deadline. I also like being given a lot of freedom in this coursework. It doesn't feel like a piece of work- it feels fun!”

"Enjoyed doing the poster presentation as I think research skills will come useful in the future - especially on placement”

“Team work is key in this assignment”, (cited skills learnt) "ability to present to a larger group of people than before, team work, delegation to each team members' strengths.” (cited skills learnt) "Voice projecting and working with a larger audience”

(cited skills learnt) "Team work skills. The presentation is particularly helpful to improve that.” "presenting in big group as it built confidence" 